\title{
Assessing the validity and acceptability of DietPhone as a dietary measurement tool in adolescent girls
}

\author{
A. Hickman, K. Aitchison, H. I. M. Davidson and M. E. Clapham \\ Health Sciences, Queen Margaret University, Edinburgh EH21 6UU, UK
}

Dietary assessment is essential for investigating the relationship between diet and disease. Previously, it has been assumed that dietary measures used in adults were appropriate in younger age groups. However, research has highlighted that measuring the diets of adolescents, in particular, poses unique challenges ${ }^{(1)}$. It has been suggested the development of new and innovative techniques for obtaining dietary intakes of adolescents could improve the accuracy of reporting in this age group. This study aims to investigate whether DietPhone is a valid dietary assessment tool and whether it is acceptable to use with adolescents.

DietPhone is an application downloadable onto mobile phone handsets. It has been developed and designed by staff at Queen Margaret University to record dietary intake. It contains the complete food database published by the FSA ${ }^{(2)}$. DietPhone is essentially the same selfreport dietary intake method as diet diaries.

Eleven girls aged 12 to 13 years old kept a 5-d dietary record using both diet diaries and DietPhone over separate time periods. Comparisons of the mean daily intakes of energy, carbohydrate and calcium were made between the two methods. Using the Bland and Altman $^{(3)}$ technique, the level of relative agreement between the two methods was determined. Additionally, focus groups were carried out to establish whether this group found DietPhone to be an acceptable way of monitoring their diets.

At the group level, analysis revealed good agreement between the two methods for carbohydrate, with a mean difference of $15.9 \mathrm{~g}$, ( $95 \%$ CI $-78.8 \mathrm{~g}$ to $110.6 \mathrm{~g}$ ) being observed. However, there appears to be a lack of agreement for intakes of energy, and calcium, with mean differences of $706 \mathrm{~kJ}(95 \% \mathrm{CI}-2010 \mathrm{~kJ}$ to $3419 \mathrm{~kJ})$ and $72 \mathrm{mg}$, (95\% CI $-236 \mathrm{mg}$ to $379 \mathrm{mg})$, respectively. At an individual level, wide limits of agreement were observed for all the nutritional parameters measured, suggesting a lack of agreement at the individual level. Nevertheless, DietPhone was established as the preferred method of choice during the focus groups. In addition, the group identified several modifications that could ultimately improve DietPhone.

Due to the lack of agreement observed between the two methods, it is not appropriate to recommend replacing diet diaries with DietPhone as a dietary assessment tool at this time. However, it appears that participants enjoyed using DietPhone and it was favoured over using diet diaries, suggesting this technology is acceptable to use with this population. Mobile phones are lightweight, portable, practical to carry around and prominent enough to act as a reminder to record data. DietPhone removes the need to record on paper after eating, thus reducing the burden and embarrassment associated with completing diaries. Additionally, it cuts down on the cost and difficulties involved in distributing diet diaries to participants. Therefore, with further development, DietPhone has the potential to be used to assess the dietary intakes of adolescents.

1. Livingstone MBE, Robson PJ \& Wallace JM (2004) Issues in dietary intake assessment of children and adolescents. Br J Nutr 92, Suppl., S213-S222.

2. Food Standards Agency (2002) McCance and Widdowson's The Composition of Foods, 6th summary edition. Cambridge: Royal Society of Chemistry.

3. Bland MJ \& Altman DG (1999) Measuring agreement in method comparison studies. Statist Methods Med Res 8, 135-160. 